\title{
Incorporating Video Visits into Ophthalmology Practice: A Retrospective Analysis and Patient Survey to Assess Initial Experiences and Patient Acceptability at an Academic Eye Center
}

\author{
Gagan Kalra - Andrew M. Williams - Patrick W. Commiskey • \\ Eve M. R. Bowers · Tadhg Schempf · José-Alain Sahel • \\ Evan L. Waxman · Roxana Fu
}

Received: May 19, 2020 / Published online: June 13, 2020

(C) The Author(s) 2020

\section{ABSTRACT}

Introduction: The coronavirus disease 2019 (COVID-19) pandemic has led to rapid adoption of teleophthalmology to deliver eyecare remotely. The purpose of our study was to assess the implementation and patient acceptability of video consultation for outpatient ophthalmic care at our institution.

Methods: We conducted a retrospective, crosssectional analysis and patient survey of adult patients who completed a virtual video visit at our institution from 18 March 18 through to 27 April 2020. All video visit encounters were assessed for patient characteristics, diagnoses,

Gagan Kalra and Andrew M. Williams are co-first authors of this study.

Evan L. Waxman and Roxana Fu are co-principal investigators of this study.

Digital Features To view digital features for this article go to https://doi.org/10.6084/m9.figshare.12417233.

\section{G. Kalra}

Government Medical College and Hospital, Chandigarh, India

A. M. Williams · P. W. Commiskey

E. M. R. Bowers - T. Schempf · J.-A. Sahel

E. L. Waxman $(\varangle) \cdot$ R. Fu $(\bowtie)$

Department of Ophthalmology, University of

Pittsburgh Medical Center, Pittsburgh, PA, USA

e-mail: waxmane@upmc.eduR. Fu

e-mail: fur3@upmc.edu management, and follow-up outcomes. Patients were surveyed for their feedback on acceptability and utility of their virtual video consultation.

Results: A total of 219 patients (mean age 55 years; range 21-89 years) completed 231 video visit encounters at our department over a 6-week period, of whom 118 were women (54\%). About half of these encounters were acute visits (102 visits, $47 \%$ ). The most common diagnosis of these visits was postoperative state (20 visits, 9\% of the total), followed by conjunctivitis (16 visits, 7\%), and keratitis (14 visits, $6 \%$ ). The most common management decisions were medication prescription (102 visits, 46\%) or reassurance (86 visits, $39 \%$ ), while 17 video visit patients $(8 \%)$ were escalated to an urgent, in-person evaluation. Ninety-two patients completed a follow-up survey (42\% response rate), of whom 45 (49\%) indicated that they might have delayed seeking care during this pandemic in the absence of a virtual video option. Seventy-two (78\%) reported that they would consider participating in a video visit as an alternative to an office-based encounter in the future, and the overall video visit experience was rated highly, with a weighted mean Likert scale rating of 4.3 out of 5 (Cronbach's $\alpha=0.88$ ).

Conclusion: Virtual video visits may be used to manage a range of ophthalmic complaints. Patients participating in this survey found such video visits acceptable and timesaving, and the 
majority would consider using video consultations for future eyecare encounters.

Keywords: Coronavirus; Coronavirus disease 2019; COVID-19; Patient-reported outcomes; Telemedicine; Teleophthalmology; Video visits; Web-based vision testing

\section{Key Summary Points}

\section{Why carry out this study?}

Video visits have been adopted rapidly in response to the COVID-19 pandemic.

The aim of this study was to assess the implementation and acceptability of virtual video visits for outpatient ophthalmic care.

\section{What was learned from this study?}

A wide range of acute and routine diagnoses were managed over the video visit encounters.

Patients rated experiences with these encounters highly, and the majority would consider using video consultations again in the future.

\section{INTRODUCTION}

In response to the global coronavirus disease 2019 (COVID-19) pandemic, ophthalmology practices have deferred routine patient visits, redesigned the clinic workflow, and limited office traffic to only urgent or emergent complaints to maximize patient and provider safety [1-3]. Accordingly, ophthalmology practices have experienced a drastic reduction in patient visits, estimated at a $79 \%$ decrease from prepandemic levels $[4,5]$.

In order to continue managing ophthalmic conditions while minimizing in-office exposure during the global pandemic, ophthalmologists have begun to adopt telemedicine into their practices. Telemedicine, the remote delivery of healthcare services via telecommunication, has had increased adoption across medical practices during the COVID-19 pandemic [6-8]. While previous teleophthalmology experiences have relied on "store-and-forward" principles of capturing patient data for later, remote assessment by ophthalmologists [9-13], the COVID-19 pandemic has prompted urgent adoption of novel, direct real-time teleophthalmology encounters.

Little is known about the utility of remote ocular examination and assessment, which typically depends on office-based equipment and testing. Implementation of remote encounters in ophthalmology is particularly challenging given the reliance on biomicroscopic examination and dependence on investigations in making diagnoses and management decisions.

The purpose of this study was to examine the implementation of virtual video visits in our ophthalmology practice by assessing visit diagnoses, management decisions, and frequency of subsequent urgent in-person encounters. Patients who participated in the video consultations were surveyed for their perspectives on the acceptability of video-based ophthalmic care.

\section{METHODS}

This retrospective chart review and cross-sectional survey was approved by the Institutional Review Board of the University of Pittsburgh Medical Center (STUDY20040002), adhered to the tenets of the Declaration of Helsinki and its later amendments, and maintained Health Insurance Portability and Accessibility Act (HIPAA) compliance. All subjects provided informed consent to participate in the survey component of the study; informed consent was waived for the retrospective chart review. No patient-identifying information is included in the manuscript.

In response to the COVID-19 pandemic, all patients who had been scheduled for an office appointment at our university practice over 6 weeks from mid-March through April 2020 were triaged by their treating ophthalmologists 
either to reschedule their appointment for 3-6 months in the future, to maintain their appointment due to high risk of vision loss, or to follow up by means of a video visit consultation [2]. Additionally, new and established patients who called with acute concerns during this time period were similarly triaged and, when appropriate, offered a video visit encounter.

\section{Video Visit Procedures}

Our video visit workflow has been described previously [2]. In brief, approximately 1 day before their scheduled visit, patients are contacted by an ophthalmic technician or optometrist to familiarize them with the video platform (Epic; Verona, WI, USA). Visual acuity is self-measured by the patient over this phone call by using a static webpage with a Rosenbaum-style eye chart (available at https:// farsight.care). By the time of the video visit, the treating ophthalmologist has the chief complaint and near visual acuity. Further examination and assessment are then performed by the ophthalmologist over the video.

\section{Video Visit Assessment}

All video visit encounters from 18 March 18 through to 27 April 2020 were included for assessment. Video visit encounters were reviewed for patient demographics, indication for visit, visit diagnosis, subspecialty service, management, and recommended follow-up. For patients with more than one video consultation, only their first encounter was included for analysis. Patients aged $<18$ years were excluded from the study.

Patient diagnoses were categorized as high risk, telemedicine appropriate, or low risk using consensus ophthalmic patient triage guidelines (https://eyewiki.org/Coronavirus_(COVID19)\#Triage_and_Scheduling_Staff). Descriptive analyses were performed.

\section{Patient Survey}

A post-encounter, 18-item online questionnaire was sent to all 219 patients who completed a video visit (Qualtrics, Provo, UT, USA). The questionnaire was structured using validated tools to assess the impact of the current pandemic, satisfaction with video visits, and experience with self-assessment of visual acuity using the farsight.care webpage [14-17]. Survey response rate was enhanced by offering a lottery-based incentive of a \$20 gift card, scheduled reminders, and an alternative, telephonebased survey. Response-weighted averages were calculated out of 5. The internal consistency of the survey was tested using Cronbach's $\alpha$.

Student's $t$ test and Pearson's correlation was used for the analysis of continuous variables. The significance level was set at $p \leq 0.05$.

\section{RESULTS}

\section{Video Visit Demographics and Diagnoses}

Over the 6-week period from 18 March through to 27 April 2020, 219 adult patients participated in 231 video visit encounters with 25 ophthalmologists. The mean age of the video visit participants was 55 (range 21-89) years and 118 (54\%) were women. Ten patients had two video visits each during this period, and one had three (Table 1). Of the 219 first-time video visit consultations, $162(74 \%)$ were with patients previously established with our practice, and 102 $(47 \%)$ were for acute rather than routine visits (Table 2).

Most video visits were conducted by the cornea (75 encounters, 34\% of all video visits), retina $(59,27 \%)$, and comprehensive services $(45,21 \%)$, with less uptake from the glaucoma $(6,3 \%)$ and neuro-ophthalmology divisions $(2$, $1 \%$ ) (Table 2).

As demonstrated in Table 2, a range of ophthalmic diagnoses was managed by video visit. Of the 87 unique diagnoses, the most common was postoperative state (20 visits, $9 \%$ of the total), generally for the 1-week or 1-month follow-up after routine cataract surgery, followed by conjunctivitis (16 visits, 7\%), and keratitis 
Table 1 Demographic characteristics of 219 adult patients who participated in video visit encounters from 18 March through to 27 April 2020

\begin{tabular}{ll}
\hline Characteristic & Statistic \\
\hline Gender, $n$ (\%) & $118(54)$ \\
Female & $101(46)$ \\
Male & \\
Age (years) & $55 \pm 18$ \\
Mean \pm standard deviation & 21,89 \\
Range & \\
Number of video visit encounters, $n(\%)$ & $208(95)$ \\
One & $10(5)$ \\
Two & $1(0.5)$ \\
Three & \\
Patient type, $n(\%)$ & $162(74)$ \\
Established & $57(26)$ \\
New & \\
\hline
\end{tabular}

(14 visits, 6\%). The triage acuity level of these diagnoses was generally moderate (151, 69\%), with an even distribution of low-acuity (33, $15 \%)$ and high-acuity encounters (35, 16\%) (Table 2).

\section{Video Visit Management and Follow-Up Outcomes}

Primary management over the video visit most commonly included prescribing medication (102 encounters, $46 \%$ of all video visits) or providing reassurance (84 encounters, 39\%). However, 17 patients (8\%) were escalated to an urgent, in-person evaluation to determine further management.

Eighteen patients $(8 \%)$ were subsequently evaluated in person within 2 weeks of their video consultation, 15 of whom had been recommended to do so. Three unprompted, inperson, follow-up encounters occurred due to persistent symptoms, and two patients were
Table 2 Characteristics of 219 video visit encounters from 18 March through to 27 April 2020

\begin{tabular}{lc}
\hline Characteristic & $\boldsymbol{n}(\%)$ \\
\hline Visit type & $117(53)$ \\
Routine & $102(47)$ \\
Problem & \\
Subspecialty service & $75(34)$ \\
Cornea & $59(27)$ \\
Retina & $45(21)$ \\
Comprehensive & $28(13)$ \\
Oculoplastics & $6(3)$ \\
Glaucoma & $3(1)$ \\
Adult motility & $2(1)$ \\
Neuro-ophthalmology & $1(0.5)$ \\
Uveitis &
\end{tabular}

Visit diagnosis $^{a}$

$\begin{array}{ll}\text { Postoperative state } & 20 \text { (9) }\end{array}$

$\begin{array}{ll}\text { Conjunctivitis } & 16(7)\end{array}$

Keratitis 14 (6)

Visual discomfort or disturbance $\quad 10(4)$

Iritis 8 (3)

Cataract $\quad 7$ (3)

Age-related macular degeneration 6 (3)

Corneal ulcer $6(3)$

Diabetic eye disease 6 (3)

Dry eye $6(3)$

Scleritis/episcleritis 6 (3)

Serous retinal detachment 6 (3)

Glaucoma $\quad 5(2)$

Herpetic eye disease 5 (2)

Retinal hole $5(2)$

Chalazion 4 (2)

Thyroid eye disease 4 (2)

Blepharitis $3(1)$

Epiphora 3 (1) 
Table 2 continued

\begin{tabular}{lc}
\hline Characteristic & $n(\%)$ \\
\hline Eyelid disorder & $3(1)$ \\
Eyelid edema & $3(1)$ \\
Orbital fracture & $3(1)$ \\
Other oculoplastic disorder & $3(1)$ \\
Diagnoses unique to $\leq 2$ encounters & $64(28)$ \\
Unspecified diagnosis & $15(6)$ \\
Triage acuity level of diagnosis ${ }^{\mathrm{b}}$ & \\
Low & $33(15)$ \\
Moderate & $151(69)$ \\
High & $35(16)$ \\
\hline
\end{tabular}

For patients who participated in more than one video visit over this timeframe, only characteristics of the first video visit encounter were included; $n$ refers to number of video visit encounters

a Includes only diagnoses made in $>2$ encounters

b Triage acuity level of diagnosis was determined by referencing consensus of the larger ophthalmology community (available at https://eyewiki.org/Coronavirus_ (COVID-19)\#Triage_and_Scheduling_Staff)

recommended an urgent office visit but were lost to follow-up (Table 3).

\section{Patient Perspectives}

Of the 219 video visit patients invited to take parts in our survey, 92 (42\%) responded. Of these 92 respondents, only 48 (52\%) patients opted for the US\$20 lottery. Forty-five respondents (49\%) indicated that they might have delayed seeking care if not for option of the video consultation, and 62 (67\%) reported that the video visits eased fears about potential vision loss.

Patient responses to questions about their video visit experience are shown in Table 4. Patients were asked to compare their video visit experience with that of traditional office appointments on a Likert scale from 1 to 5 , with 3 indicating no difference and higher ratings favoring video visits. Compared to in-person visits, patients found video visits to be more convenient (mean rating 4.4, $n=92$ ), equally effective (mean rating 3.8, $n=91$ ), and more timesaving (mean rating $4.5, n=91$ ). Specifically, 80 patients $(87 \%)$ indicted that they saved time by participating in a video visit compared to an in-person encounter, 45 of whom (57\%) estimated that they saved $>1 \mathrm{~h}$. Cronbach's $\alpha$ was 0.88 , indicating good internal consistency of survey results.

Overall experience with video visits was favorable (mean rating 4.3, $n=92$ ) (Table 4). Moreover, 72 patients (78\%) indicated that they would consider a video visit as an alternative to an in-person visit for ophthalmic care in the future.

\section{Web-Based Visual Acuity Measurement Using the farsight.care Webpage}

Measurement of visual acuity using the farsight.care webpage (https://farsight.care) was documented in 116 of 231 (50\%) video visit encounters. Patient-reported experience with self-measured visual acuity was favorable, with patients rating their experience with this method of acuity testing as 4 out of 5 for time saved, money saved, and ease of use (Table 5), with a Cronbach's $\alpha$ of 0.91, indicating good internal consistency. There was no significant difference in age between the 116 video visit patients who completed visual acuity testing using the farsight.care webpage (54 years) and the 115 who did not (56 years; $p=0.409$ ).

\section{DISCUSSION}

We describe our institution's implementation of video visits as a means to continue delivering ophthalmic care during the COVID-19 pandemic, identifying a wide range of diagnoses managed and finding high levels of patient acceptance for video-based eyecare in a postencounter survey.

The use of real-time audiovisual telecommunication to deliver care directly between 
Table 3 Management and outcomes of 219 video visit encounters from 18 March through to 27 April 2020

\begin{tabular}{ll}
\hline Characteristic & $\boldsymbol{n}(\%)$ \\
\hline Management via video visit & $102(46)$ \\
Medication dispensed & $84(39)$ \\
Reassurance & $11(5)$ \\
In-person follow-up recommended & $7(3)$ \\
Operative procedure arranged & $6(3)$ \\
Laboratory tests or imaging examinations ordered & $5(2)$ \\
Referral placed & $2(1)$ \\
Procedure arranged & $2(1)$ \\
Decision to delay previously scheduled surgery & $17(8)$ \\
In-person follow-up & $15(88)$ \\
Recommended within 2 weeks & $3(1)$ \\
Completed if recommended within 2 weeks & \\
Unprompted within 2 weeks of video visit & \\
\hline
\end{tabular}

Table 4 Survey responses from 92 patients on their video visit experiences (Cronbach's $\alpha=0.88$ )

\begin{tabular}{ll}
\hline Question (number of respondents) & $\begin{array}{l}\text { Likert score }{ }^{\text {a }} \text { (weighted } \\
\text { mean } \pm \text { wSD) }\end{array}$ \\
\hline Compared to your regular consult visits, how convenient was your video visit? $(n=92)$ & $4.4 \pm 1.1$ \\
$\begin{array}{l}\text { Compared to your regular consult visits, how timesaving was planning and executing } \\
\text { your video visit? }(n=91)\end{array}$ & $4.5 \pm 0.8$ \\
Compared to your regular consult visits, how effective was your video visit? $(n=91)$ & $3.8 \pm 0.9$ \\
Rate your overall experience meeting your doctor using the video visit $(n=92)$ & $4.3 \pm 0.9$ \\
\hline
\end{tabular}

wSD Weighted standard deviation

${ }^{a}$ Likert scale from 1 to 5 , with 3 indicating no difference and higher ratings favoring video visits

patient and physician is new to ophthalmology. Previous teleophthalmology programs have utilized "store-and-forward" models, whereby images are obtained for remote assessment by an interpreting ophthalmologist $[9,11-13,18,19]$. Other attempts at real-time communication have required patients to visit a telemedicine-capable site at the recommendation of a referring primary care provider (Table 6) [20-25]. Direct, real-time synchronous teleophthalmology, while not previously described from an academic outpatient practice [26], has allowed our ophthalmologists to continue providing patient care and to screen new patient concerns during the global pandemic. The implementation of video visits for ophthalmic care has been made possible with improved telecommunication systems and increased household access to smartphones and webcam-enabled devices.

Reports from other medical specialties demonstrate that direct video consultations 
Table 5 Satisfaction ratings of 53 patients who used the web-based eye chart to measure visual acuity (Cronbach's $\alpha=0.91)$

\begin{tabular}{ll}
\hline Satisfaction with... & Likert score ${ }^{\text {a }}$ (weighted mean \pm wSD) \\
\hline Time saved & $3.9 \pm 1.0$ \\
Money saved & $4.0 \pm 1.0$ \\
Convenience and ease of use & $4.1 \pm 0.9$ \\
\hline
\end{tabular}

The farsight.care webpage used by the patient to measure visual acuity is available at https://farsight.care wSD Weighted standard deviation

a Likert scale from 1 to 5 , with higher ratings showing increasing satisfaction

yield high patient satisfaction with similar outcomes and higher cost-efficacy ratios compared to standard, in-person visits [27-31]. Future studies are needed to better elucidate if there are similar outcome and complication rates of video visit patients in ophthalmology.

Direct, real-time, video visits have not previously demonstrated efficacy or acceptability for use in ophthalmic care. The current study indicates that our physicians were able to make a management decision by video visits in $92 \%$ of encounters (deferring 8\% to an urgent, inperson visit) and that patients rated their video visit experiences highly. The majority of patients would elect for another video visit over an office-based encounter for their future eye care.

\section{Outcome Measures}

The psychosocial impact of the COVID-19 pandemic is concerning [32-34]. In fact, approximately half $(49 \%)$ of our patients felt they would have delayed seeking care if not for video visits during this time. Nearly two-thirds reported that their fears and frustrations were eased by consulting with their ophthalmologist over a video visit.

Video visit outcomes were also assessed by measuring the number of patients who subsequently required in-person follow-up. We noted that $18(8 \%)$ of the 219 video visit patients were evaluated in person within 2 weeks, most at the recommendation of their treating ophthalmologist. Notably, however, three patients presented urgently to the office due to persistent symptoms that they felt were inadequately addressed by video alone. Understanding changes in clinical outcomes from delays in monitoring chronic conditions require further research, and analysis is ongoing in this area.

Video visits were well received by patients, who reported high satisfaction with the convenience, time-saved, and effectiveness of the visits. The high rating for overall experience with these video visits is consistent with previously reported satisfaction ratings from video encounters in other specialties [27-31].

\section{Self-Measurement of Visual Acuity Using the farsight.care Webpage}

To provide visual acuity assessment for video visits, our department designed and implemented a static webpage with a Rosenbaumstyle eye chart (available at https://farsight. care). While smartphone application-based vision testing has previously demonstrated moderate agreement with office-based visual acuity measurements [35-37], we sought a webbased alternative in order to avoid the inconvenience of installation and setup requirements. Our webpage eyechart was successfully implemented in over half of our video visit encounters and was well received by patients, who rated the tool 4.1 out of 5 for its convenience and ease of use. 


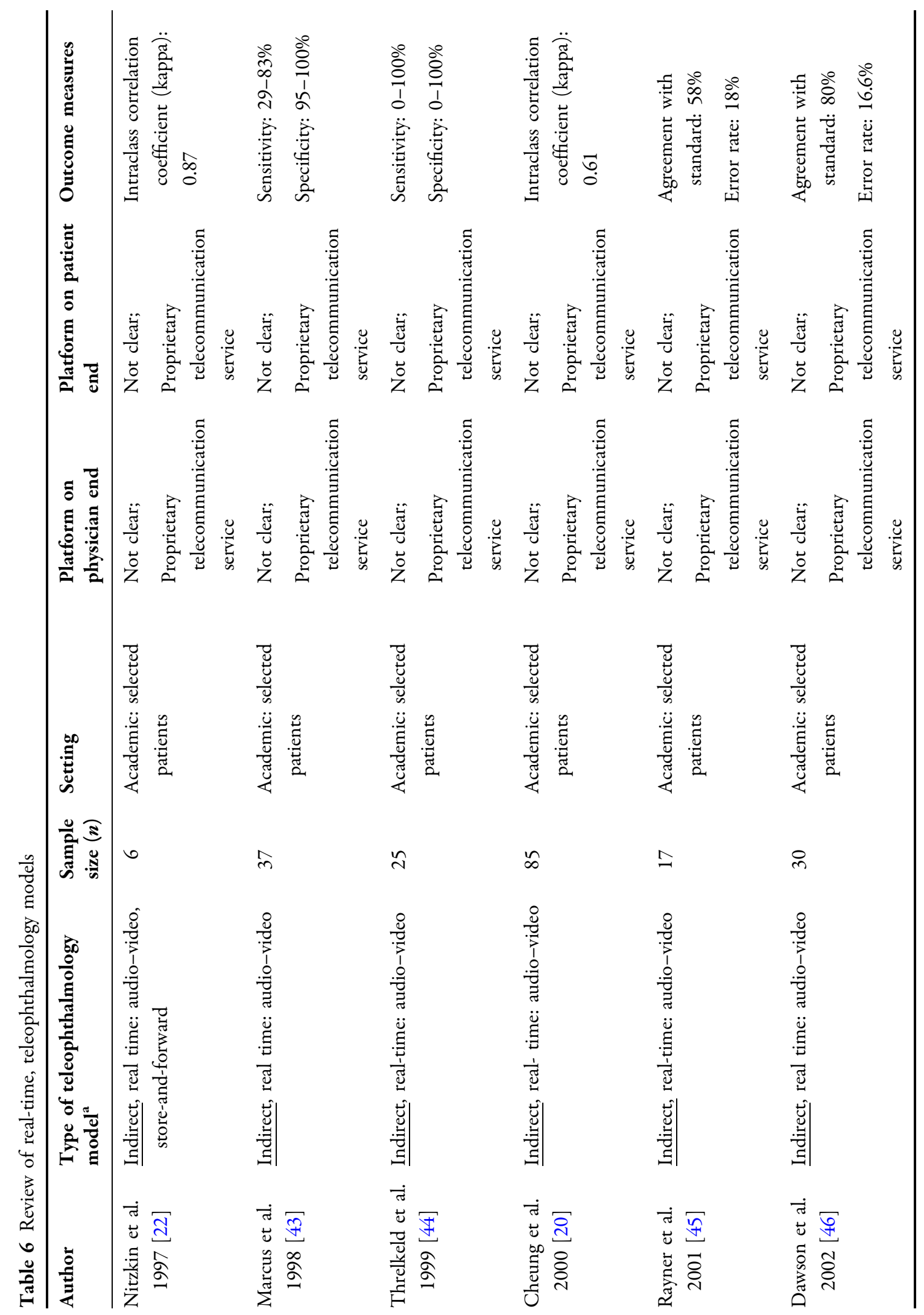




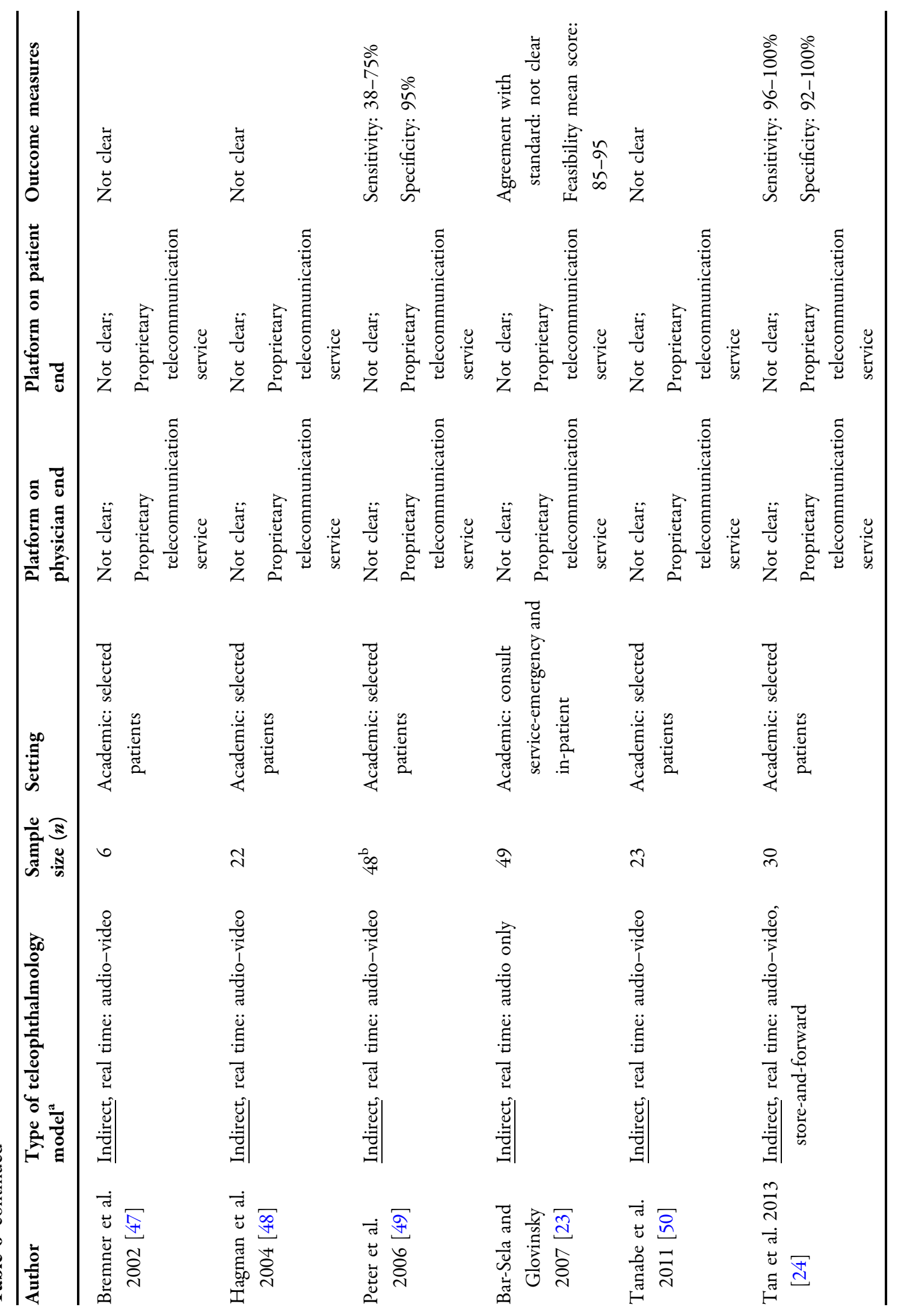




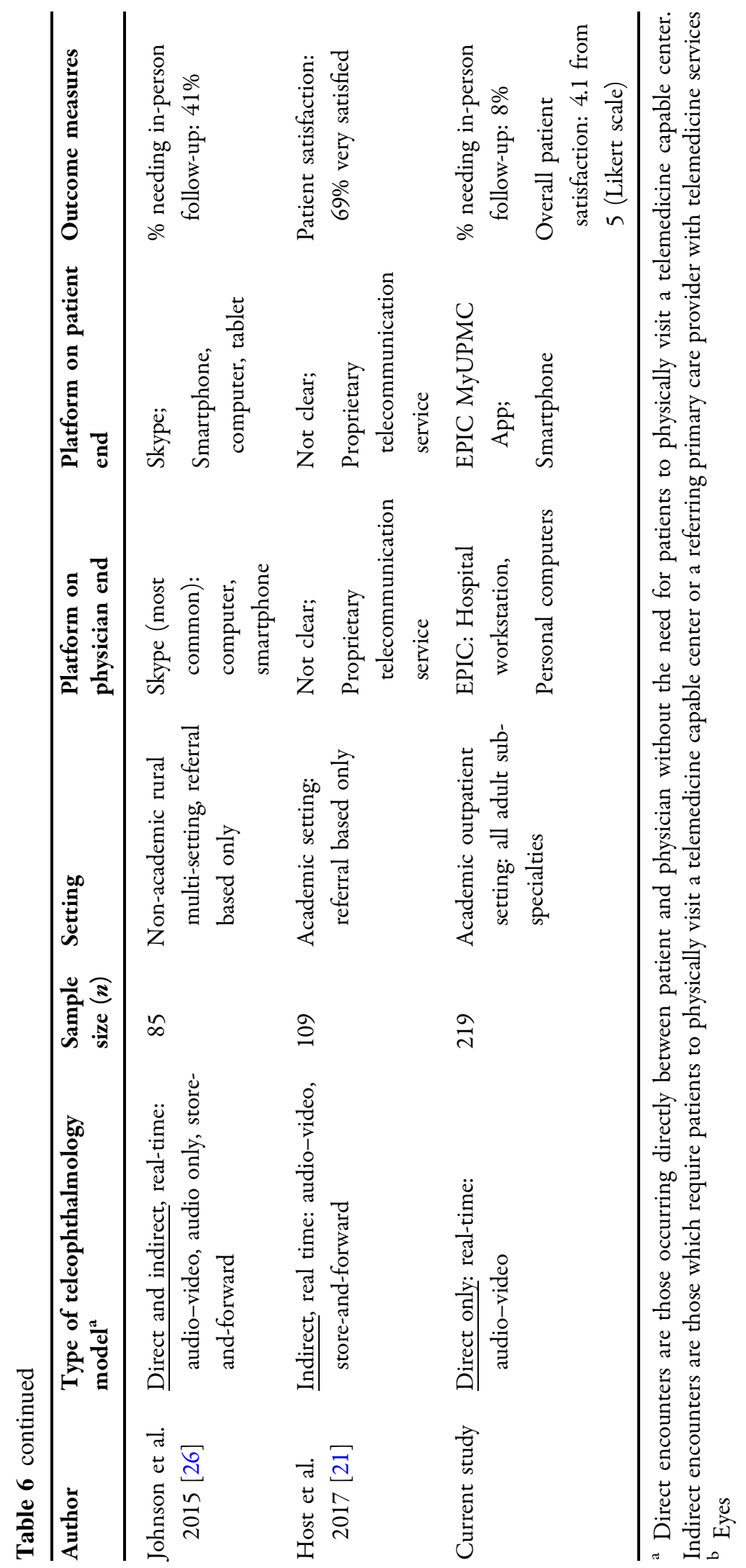




\section{Video Visit Limitations}

The implementation of video visit encounters is especially challenging in ophthalmology, which depends on an intricate examination and relies on testing, such as refraction, tonometry, perimetry, and imaging, for making management decisions. Video visits cannot replace direct consultation involving a slit-lamp examination, and ophthalmologists will have to exercise caution in determining the circumstances in which a video visit is appropriate for triage or routine follow-up. Concerns about technical intricacies, clinical quality, misdiagnosis, and privacy will need to be addressed for widespread implementation of video-based eye exams [38-41]. For a large-scale implementation, a suitable, secure, reliable and userfriendly video visit platform is essential [42]. Despite these inherent limitations, we found that ophthalmologists were able to manage a range of concerns over video visits during this time of clinic disruption.

\section{Study Limitations}

To our knowledge, our study is the first to report a large series of video-based out-patient encounters in an academic ophthalmology practice. However, we recognize that this study has a number of limitations. While video visits and the farsight.care webpage received positive patient feedback, these tools are not yet validated compared to their standard office-measured counterparts. Additionally, 52\% of responders had opted for our incentive for completing the patient survey. This may have resulted in biased responses, although our lottery-based incentive for a \$20 gift card is not unduly generous. Survey response bias could also have skewed results. Although our response rate of $42 \%$ is high for a patient-feedback survey, it is possible that the respondents may not be totally representative of all video visit patients. Finally, experiences and outcomes from a single academic center may not be generalizable to general ophthalmic practice.

\section{CONCLUSION}

Video visits were successfully implemented in our multispecialty, academic ophthalmology practice for acute visit triage and stable followup appointments. Patients rated their experiences with these encounters highly, and most complaints were addressed by video visit alone. The rate of conversion to an in-person visit was low, suggestive of successful triage and remote management.

More research is needed to determine the long-term outcomes of video visits for patients and practices. Despite their limitations and challenges, the convenience and acceptability of video visits may cause virtual ophthalmic encounters to persist well beyond the pandemic that prompted their implementation.

\section{ACKNOWLEDGEMENTS}

We thank the participants of the study.

Funding. No funding or sponsorship was received for this study or publication of this article.

Authorship. All named authors meet the International Committee of Medical Journal Editors (ICMJE) criteria for authorship for this article, take responsibility for the integrity of the work as a whole, and have given their approval for this version to be published.

Disclosures. Gagan Kalra, Andrew M. Williams, Patrick W. Commiskey, Eve M. R. Bowers, Tadhg Schempf, José-Alain Sahel, Evan L. Waxman, and Roxana $\mathrm{Fu}$ declare no potential conflicts of interest in relation to this work.

Compliance with Ethics Guidelines. This retrospective chart review and cross-sectional survey was approved by the Institutional Review Board of the University of Pittsburgh Medical Center (STUDY20040002), adhered to the tenets of the Declaration of Helsinki and its later amendments, and maintained Health Insurance Portability and Accessibility Act 
(HIPAA) compliance. All subjects provided informed consent to participate in the survey component of the study; informed consent was waived for the retrospective chart review. No patient-identifying information is included in the manuscript.

Data Availability. The datasets generated during and/or analyzed during the current study are available from the corresponding author on reasonable request.

Open Access. This article is licensed under a Creative Commons Attribution-NonCommercial 4.0 International License, which permits any non-commercial use, sharing, adaptation, distribution and reproduction in any medium or format, as long as you give appropriate credit to the original author(s) and the source, provide a link to the Creative Commons licence, and indicate if changes were made. The images or other third party material in this article are included in the article's Creative Commons licence, unless indicated otherwise in a credit line to the material. If material is not included in the article's Creative Commons licence and your intended use is not permitted by statutory regulation or exceeds the permitted use, you will need to obtain permission directly from the copyright holder. To view a copy of this licence, visit http://creativecommons.org/licenses/bync/4.0/

\section{REFERENCES}

1. American Academy of Ophthalmology. New recommendations for urgent and nonurgent patient care. 2020. https://www.aao.org/headline/newrecommendations-urgent-nonurgent-patient-care. Accessed 8 Apr 2020.

2. Williams AM, Kalra G, Commiskey PW, et al. Ophthalmology practice during the coronavirus disease 2019 pandemic: The University of Pittsburgh Experience in promoting clinic safety and embracing video visits. Ophthalmol Ther. 2020;6: $1-9$.

3. Parravano M, Borrelli E, Costanzo E, Sacconi R, Varano M, Querques G. Protect healthcare workers and patients from COVID-19: the experience of two tertiary ophthalmology care referral centers in Italy. Ophthalmol Ther. 2020;9:9(2):231-4.

4. The Commonwealth Fund. What impact has COVID-19 had on outpatient visits? 2020. https:// www.commonwealthfund.org/publications/2020/ apr/impact-covid-19-outpatient-visits. Accessed 2 May 2020.

5. Nair AG, Gandhi RA, Natarajan S. Effect of COVID19 related lockdown on ophthalmic practice and patient care in India: results of a survey. Indian J Ophthalmol. 2020;68(5):725-30.

6. Hollander JE, Carr BG. Virtually perfect? Telemedicine for Covid-19. N Engl J Med. 2020;382(18): 1679-81.

7. Chauhan V, Galwankar S, Arquilla B, et al. Novel coronavirus (COVID-19): leveraging telemedicine to optimize care while minimizing exposures and viral transmission. J Emerg Trauma Shock. 2020;13(1):20.

8. Ohannessian R, Duong TA, Odone A. Global telemedicine implementation and integration within health systems to fight the COVID-19 pandemic: a call to action. JMIR Public Health Surveill. 2020;6(2):e18810.

9. Ting DS, Gunasekeran DV, Wickham L, Wong TY. Next generation telemedicine platforms to screen and triage. Br J Ophthalmol. 2020;104(3):299-300.

10. Nguyen HV, Tan GS, Tapp RJ, et al. Cost-effectiveness of a national telemedicine diabetic retinopathy screening program in Singapore. Ophthalmology. 2016;123(12):2571-80.

11. Labiris G, Fanariotis M, Christoulakis C, et al. Teleophthalmology and conventional ophthalmology using a mobile medical unit in remote Greece. J Telemed Telecare. 2003;9(5):296-9.

12. Mohammadpour M, Heidari Z, Mirghorbani M, Hashemi H. Smartphones, tele-ophthalmology, and VISION 2020. Int J Ophthalmol. 2017;10(12):1909.

13. Paul PG, Raman R, Rani PK, Deshmukh H, Sharma T. Patient satisfaction levels during teleophthalmology consultation in rural South India. Telemed J e-Health. 2006;12(5):571-8.

14. De Boer MR, Moll AC, De Vet HC, Terwee CB, Völker-Dieben HJ, Van Rens GH. Psychometric properties of vision-related quality of life questionnaires: a systematic review. Ophthalmic Physiol Opt. 2004;24(4):257-73.

15. Miljanović B, Dana R, Sullivan DA, Schaumberg DA. Impact of dry eye syndrome on vision-related 
quality of life. Am J Ophthalmol. 2007;143(3): 409-15.

16. Freeman EE, Muñoz B, West SK, Jampel HD, Friedman DS. Glaucoma and quality of life: the salisbury eye evaluation. Ophthalmology. 2008;115(2): 233-8.

17. Frost N, Sparrow J, Durant J, Donovan J, Peters T, Brookes S. Development of a questionnaire for measurement of vision-related quality of life. Ophthalmic Epidemiol. 1998;5(4):185-210.

18. Sreelatha OK, Ramesh SV. Teleophthalmology: improving patient outcomes? Clin Ophthalmol. 2016;10:285-95.

19. Silva PS, Horton MB, Clary D, et al. Identification of diabetic retinopathy and ungradable image rate with ultrawide field imaging in a national teleophthalmology program. Ophthalmology. 2016;123(6):1360-7.

20. Cheung JC, Dick PT, Kraft SP, Yamada J, Macarthur C. Strabismus examination by telemedicine. Ophthalmology. 2000;107(11):1999-2005.

21. Host BKJ, Turner AW, Muir J. Real-time teleophthalmology video consultation: an analysis of patient satisfaction in rural Western Australia. Clin Exp Optom. 2018;101(1):129-34.

22. Nitzkin JL, Zhu N, Marier RL. Reliability of telemedicine examination. Telemed J. 1997;3(2): 141-57.

23. Bar-Sela SM, Glovinsky Y. A feasibility study of an Internet-based telemedicine system for consultation in an ophthalmic emergency room. J Telemed Telecare. 2007;13(3):119-24.

24. Tan JC, Poh EW, Srinivasan S, Lim TH. A pilot trial of tele-ophthalmology for diagnosis of chronic blurred vision. J Telemed Telecare. 2013;19(2):65-9.

25. Tan IJ, Dobson LP, Bartnik S, Muir J, Turner AW. Real-time teleophthalmology versus face-to-face consultation: a systematic review. J Telemed Telecare. 2017;23(7):629-38.

26. Johnson KA, Meyer J, Yazar S, Turner AW. Real-time teleophthalmology in rural Western Australia. Aust J Rural Health. 2015;23(3):142-9.

27. Backhaus A, Agha Z, Maglione ML, et al. Videoconferencing psychotherapy: a systematic review. Psychol Serv. 2012;9(2):111.

28. Greenhalgh T, Wherton J, Shaw S, Morrison C. Video consultations for covid-19. BMJ. 2020;368: m998.
29. Abimbola S, Keelan S, Everett M, et al. The medium, the message and the measure: a theory-driven review on the value of telehealth as a patient-facing digital health innovation. Health Econ Rev. 2019;9(1):21.

30. Ignatowicz A, Atherton $\mathrm{H}$, Bernstein $\mathrm{CJ}$, et al. Internet videoconferencing for patient-clinician consultations in long-term conditions: a review of reviews and applications in line with guidelines and recommendations. Digit Health. 2019;5: 2055207619845831.

31. Armfield NR, Bradford M, Bradford NK. The clinical use of Skype-for which patients, with which problems and in which settings? A snapshot review of the literature. Int J Med Inform. 2015;84(10): 737-42.

32. Hou Z, Du F, Jiang H, Zhou X, Lin L. Assessment of public attention, risk perception, emotional and behavioural responses to the COVID-19 outbreak: social media surveillance in China. Risk perception, emotional and behavioural responses to the COVID-19 outbreak: social media surveillance in China. 2020. https://doi.org/10.2139/ssrn.3551338.

33. Chen Q, Liang M, Li Y, et al. Mental health care for medical staff in China during the COVID-19 outbreak. Lancet Psychiatry. 2020;7(4):e15-e1616.

34. Depoux A, Martin S, Karafillakis E, Preet R, WilderSmith A, Larson H. The pandemic of social media panic travels faster than the COVID-19 outbreak. J Travel Med. 2020. https://doi.org/10.1093/jtm/ taaa031.

35. Han X, Scheetz J, Keel S, et al. Development and validation of a smartphone-based visual acuity test (vision at home). Transl Vis Sci Technol. 2019;8(4): 27.

36. Bastawrous A, Rono HK, Livingstone IA, et al. Development and validation of a smartphonebased visual acuity test (peek acuity) for clinical practice and community-based fieldwork. JAMA Ophthalmol. 2015;133(8):930-7.

37. Rodríguez-Vallejo M. Comment on: 'effectiveness of a smartphone application for testing near-visual acuity'. Eye. 2016;30(6):898-9.

38. Alami H, Gagnon M-P, Wootton R, Fortin J-P, Zanaboni P. Exploring factors associated with the uneven utilization of telemedicine in Norway: a mixed methods study. BMC Med Inform Decis Mak. 2017;17(1):180.

39. Shaw S, Wherton J, Vijayaraghavan S, Morris J, Bhattacharya S, Hanson P, et al. Advantages and limitations of virtual online consultations in a NHS acute trust: the VOCAL mixed-methods study. 
Health Serv Deliv Res. 2018. https://doi.org/10. 3310/hsdr06210.

40. Donaghy E, Atherton H, Hammersley V, et al. Acceptability, benefits, and challenges of video consulting: a qualitative study in primary care. Br J Gen Pract. 2019;69(686):e586-e594594.

41. Sturesson L, Groth K. Effects of the digital transformation: qualitative study on the disturbances and limitations of using video visits in outpatient care. J Med Internet Res. 2018;20(6):e221.

42. Mann DM, Chen J, Chunara R, Testa PA, Nov O. COVID-19 transforms health care through telemedicine: evidence from the field. J Am Med Inform Assoc. 2020. https://doi.org/10.1093/jamia/ ocaa072.

43. Marcus DM, Brooks SE, Ulrich LD, et al. Telemedicine diagnosis of eye disorders by direct ophthalmoscopy. A pilot study. Ophthalmology. 1998;105(10):1907-14.

44. Threlkeld AB, Fahd T, Camp M, Johnson MH. Telemedical evaluation of ocular adnexa and anterior segment. Am J Ophthalmol. 1999;127(4): 464-6.
45. Rayner S, Beaconsfield M, Kennedy C, Collin R, Taylor P, Murdoch I. Subspecialty adnexal ophthalmological examination using telemedicine. J Telemed Telecare. 2001;7(Suppl 1):29-31.

46. Dawson E, Kennedy C, Bentley C, Lee J, Murdoch I. The role of telemedicine in the assessment of strabismus. J Telemed Telecare. 2002;8(1):52-5.

47. Bremner F, Kennedy C, Rees A, Acheson J, Murdoch I. Usefulness of teleconsultations in neuro-ophthalmology. J Telemed Telecare. 2002;8(5):305-6.

48. Hagman J, Hyytinen P, Tuulonen A. A pilot experiment using a network camera in ophthalmic teleconsultation. Acta Ophthalmol Scand. 2004;82(3 Pt 1):311-2.

49. Peter J, Piantadosi J, Piantadosi C, et al. Use of realtime telemedicine in the detection of diabetic macular oedema: a pilot study. Clin Exp Ophthalmol. 2006;34(4):312-6.

50. Tanabe N, Go K, Sakurada Y, et al. A remote operating slit lamp microscope system. Development and its utility in ophthalmologic examinations. Methods Inf Med. 2011;50(5):427-34. 